\title{
Effective Reduction in Utility Cost in A Beverage Plant
}

\author{
C.Thiagarajan, Karthick J, S.Prakash, J.Senthil, M.Prabhahar
}

\begin{abstract}
This project. is about in-depth focus on equipment power analysis and effective reduction in Utility and Quality Cost. A Value Stream Map has been developed and analyzed to identify critical focus areas in Utilities, Process and Line. The most significant key input variables have been identified and those are Boiler, Old-Utilities, New-Utilities, Process Area \& Cooling Towers, which are prioritized based upon their relationship with the key output metric. Key input, process, and output metrics have been identified. As a part of Root cause analysis, Power consumption is high due to Running of 2 compressors, yolk chiller, raw water pump, cooling tower pumps \& fan and new refrigeration for cooling tower pump. Potential implementation solutions are to be developed, evaluated, and optimized based upon their effectiveness impacting the key output, robustness to variation and ease of implementation. The final improvement solution has been incorporated into the process organization and the improvement gains of 3-25 KWH are being expected.
\end{abstract}

Keywords - Utility Cost Reduction, Beverage, Power Consumption.

\section{INTRODUCTION}

There are 2 types of compressor which works on the line: KC6 - six cylinder actuating compressor with 1 ton TR KC4 - four cylinder actuating compressor with $90 \mathrm{TR}$ On the analysis of KC6 we found that expansion valve is malfunctioning which is responsible for controlling the beverage temperature and pressure. The temperature level is not maintained due to the valve malfunction. Due to fluctuation of temperature there will be variation in bricks and it leads to a high foaming.

For running the petline SKU's we require 80-90 ton rate. Initially we were using KC6 compressor, which is a high capacity compressor which is easy to control the temperature. The temperature was not getting controlled with the existing capacity; it will be operated dually with $\mathrm{KC} 4$ stand by compressor for controlling the process temperature.

Revised Manuscript Received on September 22, 2019

* Correspondence Author

C .Thiagarajan - AssociateProfessor, Department of Mechanical Engineering, Aarupadai Veedu Institute of Technology, Vinayaka Mission Research Foundation, cthiagarajan@avit.ac.in

Karthick.J - PG Scholar, Department of Mechanical Engineering,

Aarupadai Veedu Institute of Technology, Vinayaka Mission Research Foundation, karthikj@gmail.com

S.Prakash- Research scholar, Department of Mechanical Engineering,

Aarupadai Veedu Institute of Technology, Vinayaka Mission Research Foundation, Prakash.mech94@gmail.com

J.Senthil - AssociateProfessor, Department of Mechanical

Engineering, Aarupadai Veedu Institute of Technology, Vinayaka Mission Research Foundation, jsenthil@avit.ac.in

M.Prabhahar - Professor, Department of Mechanical Engineering,

Aarupadai Veedu Institute of Technology, Vinayaka Mission Research Foundation, mprabhahar@avit.ac.in
It leads to high power consumption of $5 \mathrm{KW}$ excess per hour. After analysing overall we modified the expansion valve with three threading valve and trial the same with KC4 compressor. Which controls the temperature and pressure within the set point? As it is a 90 TR compressor it overcomes the saving of 5-6KWPH.

Line-4 refrigeration we operated $\mathrm{KC}-4$ compressor instead of $\mathrm{KC}-6$ and saved $25 \mathrm{KW} / \mathrm{Hr}$

LP compressor Set point Reduced from 6 Bar to 5 bar and saved $16 \mathrm{KW} / \mathrm{Hr}$

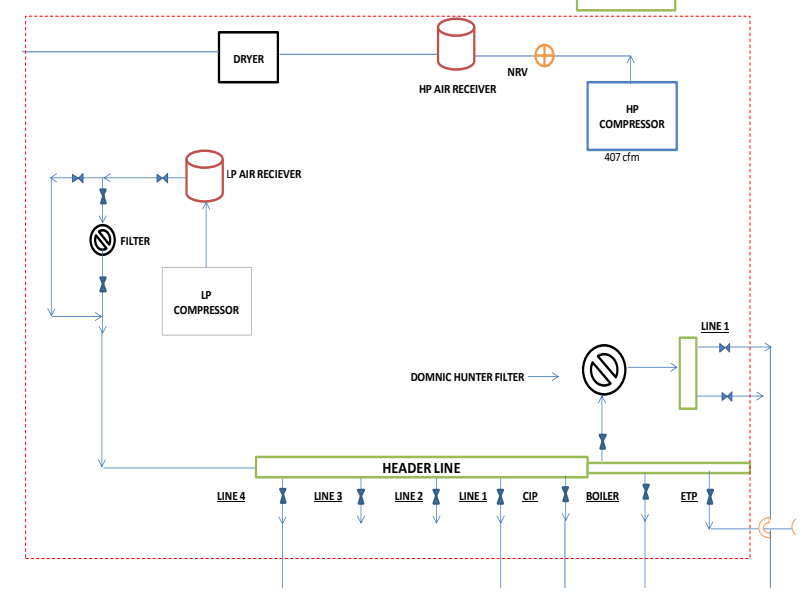

Figure 1: Flow Diagram

\section{METHEDOLOGY}

A.Power reduction on compressor

Step One: Monitor At the core of an effective keep track of program is a network of digital power monitoring devices that capture and communicate energy consumption information. These above refer devices are used to measure energy parameters associated with a specific system in Fig 1. For electricity, it may be a bus in a facility's electrical distribution system. This allows plant in charges to collect detailed information on power consumption in various areas of their plants, on specific machines (such as refrigeration compressors) and even on individual product lines. In addition to usage data, In charges have access to power quality information that can better product rate and lengthen equipment life, further intensify profits.

Examples: Different types of food \& beverage plant (WAGES) monitoring systems.

\section{B.Power monitoring systems}

A utmost advantage of a power monitoring system is its potential to capture and log real-time data and events via a high-speed control or information network over long interval of time. If Plant incharges detect compatible differences in energy usage in the same department, among different shifts or between plants with the

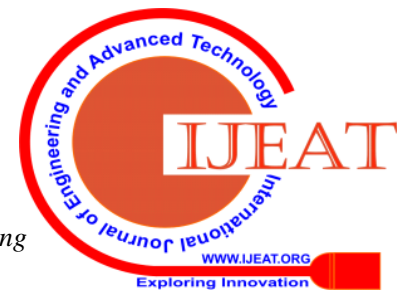


same product lines, they can examine the operation to see how lower energy results were achieved and then apply the detecting to other operations. Revenue-accurate power monitor also is useful as a reserves system to verify the billing statements issued by electric feasibilities. General type of monitoring system includes Load Profiling. In a paticular load profiling system, the desired power parameters and energy data are regularly measured and transfer by the power monitors, installed throughout the plant, via the information network to the energy management software. Above mentioned system generates large quantities of data very quickly, Information, not raw data, provides insight and understanding of power consumption profiles and patterns. Therefore, large quantity of data must be examined, matchup, and reduced into useful information to forecast, prevent and to react to electric power related issues. Developing power metrics that relate to the plant's real-time production output is an fruitful way to track and spot upsets in the system. For example tracking the ratio of millions of $\mathrm{kWh}$ consumed per shift divided by the plant's production in millions of pounds for the same shift i.e. ( $\mathrm{kWh} /$ million pounds produced). Or for air compressors $\mathrm{kWh} /$ million pounds produced is a good way to detect air leaks or lines operating at too high of a head pressure.

\section{A.Natural gas monitoring system}

A flow meter may evidence the MM-BTUs ingest by each process oven or dryer. When matchup to pounds manufacture per oven, it would permit management to track MM-BTUs eat up per pound of product produced versus a target level. This could conscious of management to hold on gas valves, burner maintenance issues or changes in baking procedures.

\section{B. Water monitoring systems}

A flow meter may record the MM-gallons of incoming water handle at the plants main incoming carbon filters. When correspond to pounds produced for the same period, a control chart of MM-gallons/MM pounds produce could be charted. This will take alert management to unnoticed water leaks, vales left open, or changes in cleaning procedures. Water consumption in food \& beverage plants may be as much as 7-10 gal of water used per gallon of end product produced. Given water scarcity and escalating water costs this type of monitoring is becoming major role for many food \& beverage producers. Waste water Monitoring Systems: A digital monitor may record MM-gallons of caustic and acid added to the plants sewage neutralization basin; as well as wastewater flow at the plant discharge point. When correlated for the same time period it may show MM-gallons of treatment chemicals/ MM-gallons discharged. A deviation from target could indicate operational problems with excessive process waste being bin to process drains or some changes in cleaning procedures. This type of monitoring can help avoid infraction of discharge permits as well as help turn down chemical treatment costs. Once a company's energy models of loads and trends are point out and charted, the possibilities are endless for manufacturers to maximize their energy savings. By tracking energy consumption patterns over time, a facility can use historical data to verify electric bills, negotiate a better rate structure and identify opportunities for demand management. A second benefit of energy monitoring systems is the potential to more accurately assign costs to specific manufacturing areas or units. Cost distribution is related to load profiling, with added functionality that allows a user to allocate energy costs to a various departments, processor facility. The above mentioned system also can generate the reports necessary to scrutinize and verify utility bills and tariffs. Personage successes can be achieved with small, non-critical adjustments in power usage with ROI achieved in a small period of time.

Electricity, for example, has various aspects of monitoring that can help designate and reduce costs.

\section{C.Sub metering}

It is the practice of redistribute power meters to monitor individual loads or work cells. In this system strategy allows users to quantify differences in power consumption from shift-to-shift or line- to-line to provide internal cost allocation. That result gives companies the capacity to recompense a specific group or department within a plant that carry out successful energy saving initiatives.

\section{D.Distribution system monitoring}

The system provides plant workers and engineers with a common view of the entire facility's power distribution system, including information for trending, alarming and targeting. It observes, engineers can pinpoint equipment approaching failure, realign electrical system topology, and manually limit demand by exfoliating loads or increasing generator output.

\section{E.Power quality monitoring}

The power quality data can be used to pinpoint failures of motors and sensitive equipment, array of better service from the utility and identify the need for power factor correction and harmonic filters. In this system, unify power quality data from distributed power monitors. The system senses voltage excursions, temporary power losses, phase reversals, and harmonics then divulge this information in the form of instantaneous displays, trends, reports and alarms.

Step Two: Examine While monitoring systems provide the foundation for the precise collecting and reporting of energy data, analysing this information enables plants to make finer decisions about controlling costs. However, in this information to make a difference in operations, it must flow smooth functionly from the plant floor to the top floor. To major benefit program is coordinating the combination of power monitoring, control devices, communication networks and visualization technologies into a unified system that relates energy consumption to plant activities. At the heart of this arrangement is an integrated architecture based on open standards that allows users to deliver energy information to wherever in the enterprise they need it. Main requirement of this architecture is the ability to leverage existing networks and devices. The ability to communicate using a variety of open networks, such as Ethernet and DeviceNet ${ }^{\mathrm{TM}}$ via wired or wireless devices enables fast data transfer and easy integration with an already available network. For example, most facilities already have an EI in place, which helps reduce installation costs. Familiar communication interfaces also are critical to help verify speed of response, support of data and efficiency of overall system performance. High-performance programmable automation controllers and advanced energy management software are also critical to supposing the analysis and control components of the solution. The controllers provide a common means of bringing discrete inputs from breakers, switches and protective relays in the electric power systems. The controllers also work in

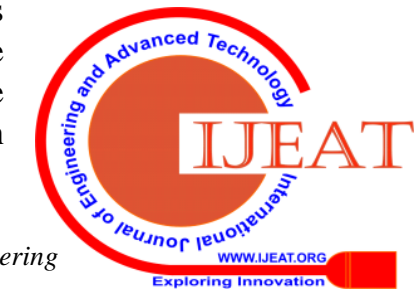


concert with the personal computers running the human machine interface (HMI) and logging software to automate data collection and concentrate data.

Step Three: Regulate after analyzing the data, plant managers can develop an action plan and install automation systems to apprehension energy savings using a number of control system options.

\section{F. Demand management systems}

Load management systems can invigilator the electrical consumption of selected equipment and turn them on and off in an operator selected proper sequence to minimize peak demand. Loads are prioritized to allow the user to configure the order in which loads should be shed and restored. Load shifting maintains a more consistent level of energy use over time, which eases demands on utilities and avoids subsequent charges. Case in point: At a large Midwestern beef and pork processing plant, meat is processed in a refrigerated facility that is kept within stringent government temperature limits. Refrigerating the 200,000 square foot plant constitutes a large portion of the connected electrical load and represents a substantial percentage of the plant's operating costs. The company pays the electric utility a "base rate" for a given consumption of kilowatt- hours. If the plant exceeds the limit, the utility assesses a "demand penalty" of up to 50 percent of the base rate. During shift start-ups, peak production times and hot summer days, electrical consumption many times exceeded "demand" thresholds, pushing the plant into the expensive peak demand range. The company needed to find a way to minimize expensive demand charges from the power company and reduce overall energy costs without compromising plant refrigeration requirements. The company's refrigeration system was controlled by an "on/off" relay-based system that was difficult to maintain and left the plant few options for conserving energy and controlling costs.

\section{G. Compressed air control and optimization systems}

The systems deliver enhanced performance of a plants air system by controlling the starting, stopping, staging and blow off functions of a system of compressors. This is happened in frequent times accomplished as part of a larger plant air audit where other actions are also taken to lesser peak air demand requirements such as isolation of single high-pressure user from the essential plant air system. With the installation of a smaller high pressure compressor it of repeatedly times allows the rest of the plant air system to be reduced by $10-15$ psi thereby reducing the main plant air system electrical consumption by $5-7$ percentage. One more action is to make food \& beverage processing and filling equipment "energy aware" by programming equipment to turn off air supply lines when product is not being produced. Often equipment is idle or temporarily down and compressed air continues to be consumed, blow on conveyors, etc. when no product is present.

\section{H. Pump optimization solution}

It can significantly shorter energy usage by employing real-time pump dispatch for industrial sites with closed loop systems that are fed by multiple parallel centrifugal pumps to a common header. Typical applications include primary and secondary chilled water loops, hot water loops.

\section{III.RESULT \& DISCUSSION}

\section{A. Reduction Of Utility Cost From 3.96 to 3.71 Rs/Cs}

Problem : Utility Cost is high against the target

Scope : Old-Utilities, New-Utilities \& Cooling Towers

Goal : The target is to work on 'Reduction of Utility cost to reduce from 3.96 to $3.71 \mathrm{Rs} / \mathrm{cs}$

Energy study in all plant Equipment's

Activating all the pump interlocks to avoid idle run. LP compressor set point reduction and placing VFD's

\section{B.Define}

\begin{tabular}{|c|l|}
\hline 5W1H & \multicolumn{1}{|c|}{ ACTION PLAN } \\
\hline What? & Utility Cost is very high against Target \\
\hline Where? & $\begin{array}{l}\text { Boiler, Old-Utilities, New-Utilities, Process } \\
\text { Area \& Cooling Towers }\end{array}$ \\
\hline Who? & Utilities ,Process and Line 4 operators \\
\hline When? & Jan'17 to March'17 \\
\hline $\begin{array}{c}\text { Which } \\
\text { Trend? }\end{array}$ & Reduced Utility cost \\
\hline How Big? & Rs/cs 3.96 to 3.71 \\
\hline
\end{tabular}

Table 1 : Define problem and Action Plan

The Project Charter has been discussed with the Project Sponsor to ensure the objectives, assumptions, and scopes of the project are clearly understood. The project team has been launched, Define Gate Review with sponsor and mentor sign-off.

\section{C.Measure Baseline}

A Value Stream Map has been developed and analyzed to identify critical focus areas and appropriate tools for the project, Key input, process, and output metrics have been identified and linked to the process map. Sufficient data has been collected to measure the baseline process performance, Quick Improvements identified and implemented, Measure Gate Review with sponsor and mentor sign-off.

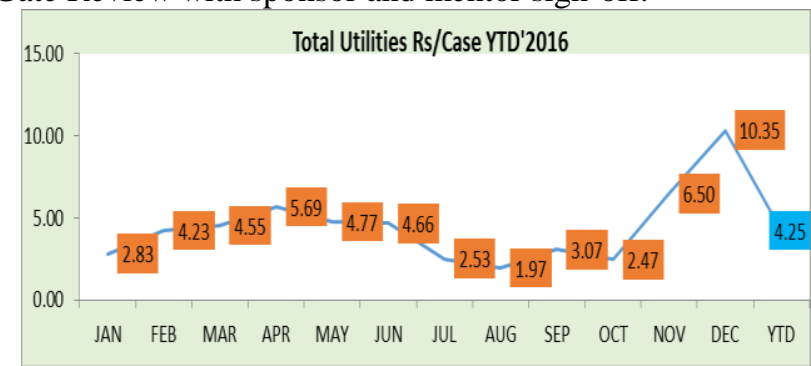

Figure 2: Total Utilities

\section{D.Analyse Objectives}

Bottlenecks or constraints on the key output have been isolated on the process map and potential cause-and-effect relationship identified. The most significant key input variables have been identified and prioritized based upon their relationship with the key output metric, The project is still properly scoped and can achieve the projected operating and financial benefits Quick Improvements identified and implemented Analyze Gate Review with sponsor and mentor sign-off. 


\section{Effective Reduction in Utility Cost in A Beverage Plant}

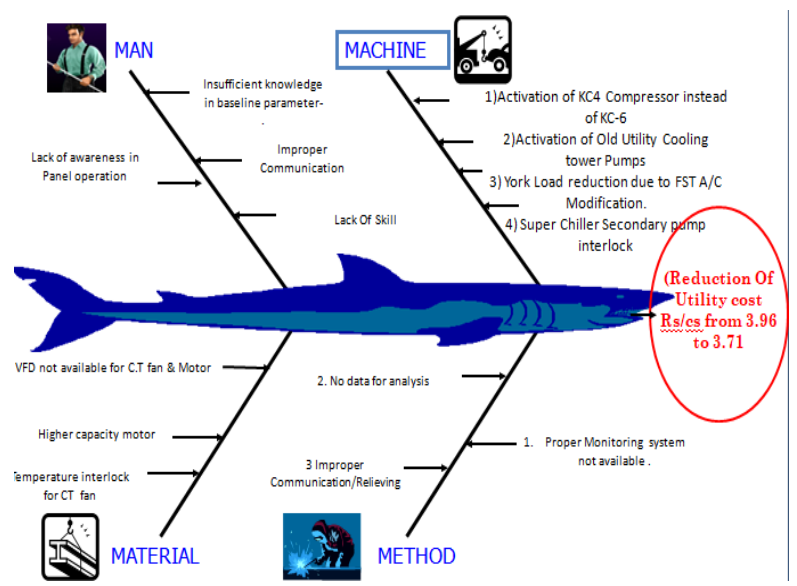

Figure 3: Fish Bone Diagram

\section{E.Implement}

Potential implementation solutions have been developed, evaluated, and optimized based upon their effectiveness impacting the key output, robustness to variation, ease of implementation, and acceptance by process owners. A Pilot Plan is developed and implemented to measure and validate the impact of the selected solution. Learnings from the pilot are incorporated into the Full Scale Implementation Plan to optimize the solution, Quick Improvements identified and implemented, Improve Gate Review with sponsor and mentor sign-off.

\begin{tabular}{|c|c|c|c|}
\hline $\begin{array}{c}\text { Sr.N } \\
\text { o }\end{array}$ & $\begin{array}{c}\text { Description of the } \\
\text { Area }\end{array}$ & Root Cause Analysis & $\begin{array}{c}\text { Result } \\
\text { Achieve } \\
\text { in Kwh }\end{array}$ \\
\hline 1 & $\begin{array}{l}\text { Running KC-4 } \\
\text { Compressor instead } \\
\text { of KC } 6 \text { Compressor }\end{array}$ & $\begin{array}{l}\text { Setting issue in } \\
\text { Expansion Valve \& } \\
\text { BPRV }\end{array}$ & 25 \\
\hline 2 & $\begin{array}{l}\text { Old Utility Cooling } \\
\text { Tower Pump }(30 \mathrm{~kW} \\
\text { Pumps) }\end{array}$ & $\begin{array}{l}\text { Soft Water Quality } \\
\text { issue }\end{array}$ & 12 \\
\hline 3 & $\begin{array}{l}\text { 400TR Cooling } \\
\text { Tower Pumps } \\
\text { Operation } \\
\text { Converted to VFD }\end{array}$ & $\begin{array}{l}\text { No VFD for Pump } \\
\text { operation }\end{array}$ & 11 \\
\hline 4 & $\begin{array}{l}\text { Temperature } \\
\text { interlock for } \\
\text { Cooling Tower Fan } \\
\text { 400TR }\end{array}$ & $\begin{array}{l}\text { No temperature } \\
\text { interlock for Cooling } \\
\text { tower fan }\end{array}$ & 3 \\
\hline 5 & $\begin{array}{l}\text { FST Room AHU } \\
\text { Converted to Duct } \\
\text { A/C }\end{array}$ & $\begin{array}{l}\text { Wrong selection in } \\
\text { Air-conditioning }\end{array}$ & 10 \\
\hline 6 & $\begin{array}{l}\text { Raw Water/Soft } \\
\text { Water Pump } \\
\text { Modification }\end{array}$ & $\begin{array}{l}\text { Higher capacity pump } \\
\text { was selected i.e head } \\
\text { issue. }\end{array}$ & 7 \\
\hline 7 & $\begin{array}{l}\text { York Load reduction } \\
\text { due to FST A/C } \\
\text { Modification. }\end{array}$ & Wrong selection in $\mathrm{AC}$ & 4 \\
\hline
\end{tabular}

Table 2 : Implement \& Result

\begin{tabular}{|c|c|c|c|c|}
\hline $\begin{array}{c}\text { Sr.n } \\
\text { o }\end{array}$ & Description of the area & $\begin{array}{c}\text { Before } \\
\text { in kwh }\end{array}$ & $\begin{array}{c}\text { After } \\
\text { in kwh }\end{array}$ & $\begin{array}{c}\text { Saving } \\
\text { in kwh }\end{array}$ \\
\hline 1 & $\begin{array}{l}\text { Running kc-4 compressor } \\
\text { instead of kc 6 compressor }\end{array}$ & 77 & 52 & 25 \\
\hline 2 & $\begin{array}{l}\text { Old utility cooling tower } \\
\text { pump (30kw pumps) }\end{array}$ & 42 & 30 & 12 \\
\hline
\end{tabular}

\begin{tabular}{|c|l|c|c|c|}
\hline 3 & $\begin{array}{l}\text { 400tr cooling tower pumps } \\
\text { operation converted to vfd }\end{array}$ & 22 & 11 & 11 \\
\hline 4 & $\begin{array}{l}\text { Temperature interlock for } \\
\text { cooling tower fan 400tr }\end{array}$ & 11 & 8 & 3 \\
\hline 5 & $\begin{array}{l}\text { Fst room ahu converted to } \\
\text { duct a/c }\end{array}$ & 18.5 & 8 & 10.5 \\
\hline 6 & $\begin{array}{l}\text { Raw water/soft water } \\
\text { pump modification }\end{array}$ & 15 & 7.5 & 7.5 \\
\hline 7 & $\begin{array}{l}\text { York load reduction due to } \\
\text { fst a/c modification. }\end{array}$ & 68 & 64 & 4 \\
\hline 9 & $\begin{array}{l}\text { Ammonia exhaust fan } \\
\text { operation automation }\end{array}$ & 3 & 0 & 3 \\
\hline 10 & $\begin{array}{l}\text { Luper chiller secondary } \\
\text { reduction interlock }\end{array}$ & 24 & 21 & 3 \\
\hline
\end{tabular}

\section{Table 3 : Implement Before \&After}

\section{F. Control objective}

Mistake proofing is incorporated into the final process whenever possible. Control plans, implementation plans, SOPs, training plans, etc. Have been developed and implemented. The final improvement solution has been incorporated into the process organization and the improvement gains are being sustained. Replication opportunities identified. Future opportunities for improvement have been properly communicated. There is a clear hand-off of the project to the process owner Calculate financial benefits.

\section{G. New utility cooling tower pump}

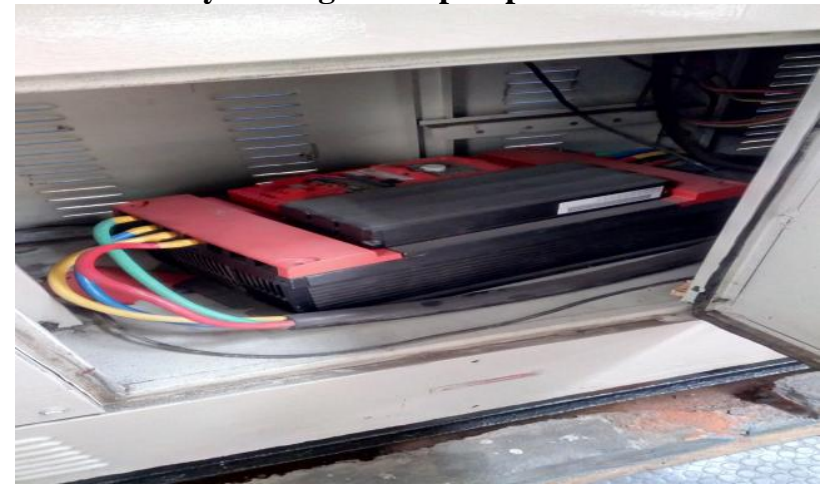

Figure 4: Cooling Tower Pump

Cooling Tower Pump operation converted into VFD and reduced Frequency. Initially when we running in Star-delta mode its consume $21 \mathrm{kw}$. After converting VFD load reduced to $10 \mathrm{KW}$. Saving Power/ Hr $11 \mathrm{KW}$.

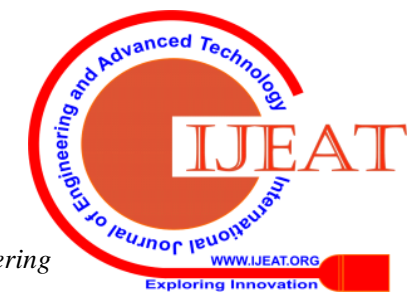




\section{H. New utility cooling tower fan}

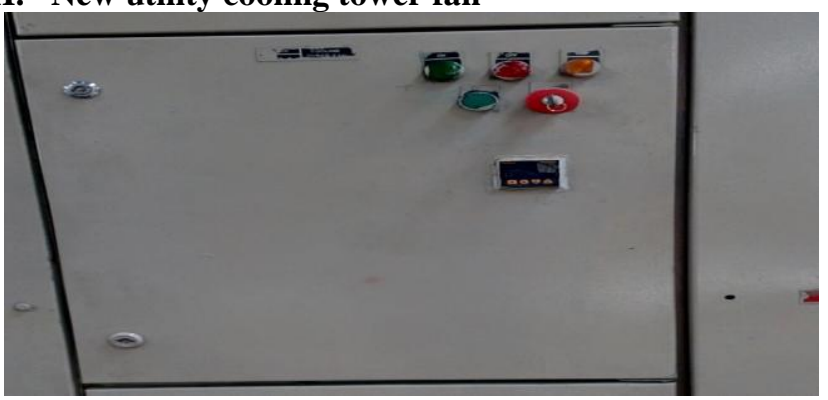

Figure 5: Cooling Tower Fan

Cooling Tower Fan operation changed to Temperature Interlock. Initially Fan will run continuously when plant running time. Now we changed to temperature interlock mode. Presently we keep Temperature 28Deg cen. whenever its reach 28 fan will be switched off automatically.

\section{Super chiller secondary pump}

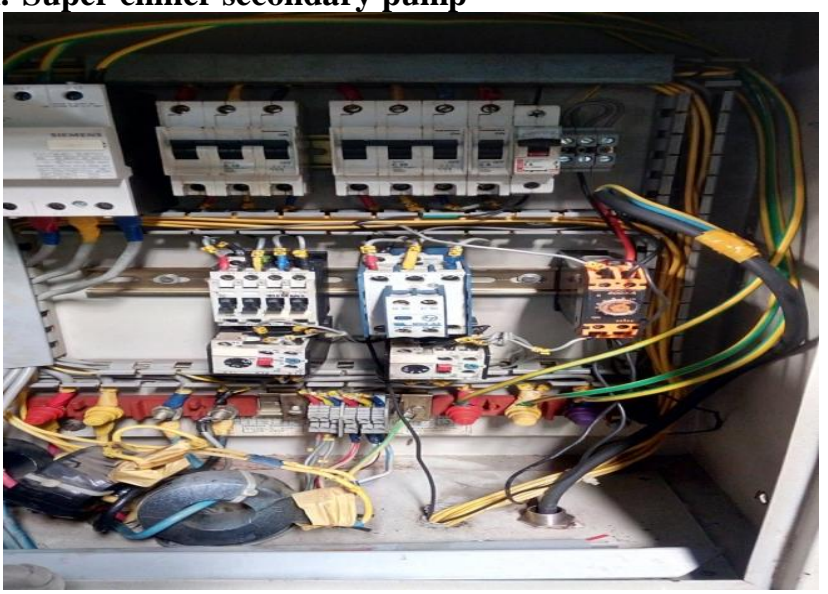

Figure 6: Secondary Pump - I

Secondary pump operation interlocked with Blow molder. Whenever BM running Pump will run. Total power saving 1 $\mathrm{KW} / \mathrm{Hr}$

\section{J. Bottle washer pump}

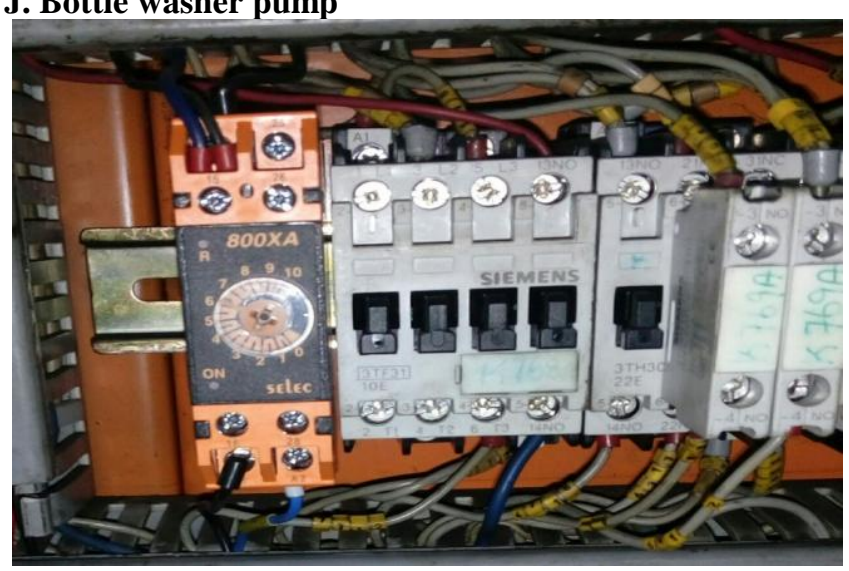

Figure 7: Secondary Pump -II

Bottle washer pump operation interlocked Bottle washer. Presently operator only switch off the pump, now pump switch off will happen will automatically. After stopping bottle washer 10th minute Pump will stop automatically. Also bottle washer start interlocked with pump.

\section{IV.CONCLUSIONS}

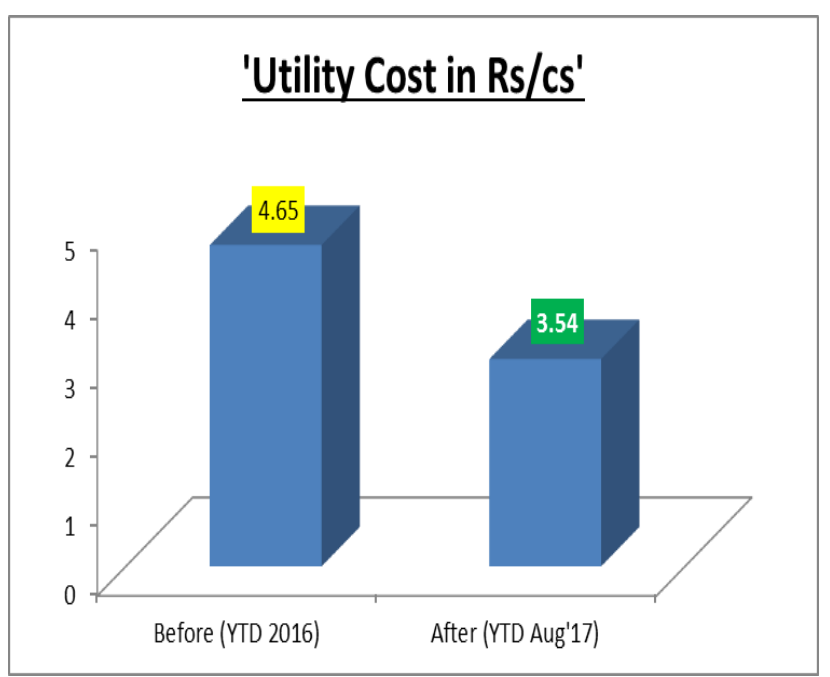

Figure 8: Utility Cost in Rs/cs

The most significant key input variables have been identified and those are Boiler, Old-Utilities, New-Utilities, Process Area \& Cooling Towers, which are prioritized based upon their relationship with the key output metric. Key input, process, and output metrics have been identified. As a part of Root cause analysis, Power consumption is high due to Running of 2 compressors, yolk chiller, raw water pump, cooling tower pumps $\&$ fan and new refrigeration for cooling tower pump. Potential implementation solutions are to be developed, evaluated, and optimized based upon their effectiveness impacting the key output, robustness to variation and ease of implementation. The final improvement solution has been incorporated into the process organization and the improvement gains of $3-25 \mathrm{KWH}$ are being expected.

\section{REFERENCES}

1. Guven Gonca ,Erinc Dobrucali ," Theoretical and experimental study on the performance of a diesel engine fueled with diesel biodiesel blends", Journal of Renewable Energy 2016.03.037/ 0960-1481/ @ 2016 Elsevier.

2. Adrian Irimescu, Simona Silvia Merola, Cinzia Tornatore, Gerardo Valentin,"Effect of coolant temperature on air-fuel mixture formation and combustion in an optical direct injection spark ignition engine fuelled with gasoline and butanol",Journal of the Energy Institute 2016.03.004/1743-9671/@ 2016 Energy Institute.

3. A.P. Manoj Kumar, J.S. Sreekumarb, P. Mohanan "The effect of cordierite/Pt catalyst on the NOx reduction in a diesel and Jatropha bio-diesel operated single cylinder engine", Journal of Environmental Chemical Engineering 2015.04.018/2213-3437/@ 2015 Elsevier.

4. N.N. Shah , M.J. Huang, N.J. Hewitt,'Experimental study of a diesel engine heat pump in heating mode for domestic retrofit application' Journal of Applied Thermal Engineering 2015.12.006/1359-4311/C 2015 Elsevier.

5. Mark P.B. Musculus, Paul C. Miles, Lyle M. Pickett, "Conceptual models for partially premixed low-temperature diesel combustion" Journal Progress in Energy and Combustion Science 2012.09.001/0360-1285/ (C) 2013 Elsevier.

6. Energy Use, Loss and Opportunities Analysis, Energetics, Inc and E3M, Inc for the U.S. Department of Energy, November 2004.

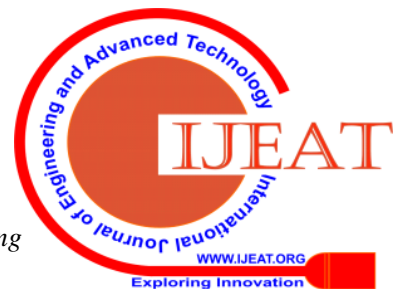

